\title{
Meteorological Forecasting and Alarming System Against Geological Disasters in Longsheng County,Guangxi Province
}

\author{
Zhixiong Wen ${ }^{1, a}$, Rongling $\mathrm{Li}^{2, \mathrm{~b}}$ and Junkang $\operatorname{Lan}^{1, \mathrm{c}}$
}

${ }^{1}$ College of Environmental Science and Engineering,Guilin University of Technology;541004,China

${ }^{2}$ Guangxi Zhuang Autonomous Region 307 Nuclear Geological Team,Guigang;China

a939001271@qq.com, b569986696@qq.com, c1269431898@qq.com

Keywords: Longsheng county; Geological disasters; Meteorological forecasting; Forecast and early warning.

Abstract. The correlation between the number of landslides and collapses and the rainfall in Longsheng county was analyzed. It was found that there were 2 inflection points in the correlation graph between the quantity of geological disasters and the rainfall. The rainfalls corresponding to the inflection points were critical rainfalls indicating abrupt changes in the number of rainfall-induced landslides and collapses. Based on these critical rainfalls, rainfall periods corresponded to high, middle and low risk grades of geological hazards in the county were divided. In order to predict the risk of geological disasters, the county is divided into different geological disaster prone areas according to disasters frequency. During disaster forcasting, the predicted daily rainfall or 3 days cumulative rainfall are first collected and checked what the rainfall period it will belong to, then a corresponding forecast chart of geological hazards is adopted to predict the risk of geological hazards in the whole county.

\section{Introduction}

The establishment of geological hazard forecasting and warning system is an active geological disaster prevention measures, which has of great significance to the effective prevention of geological disasters. So far, many provinces in China have establish their prediction and early-warning systems according to their specific geological environment conditions ${ }^{[1-4]}$. In view of the explicit statistical warning method is more suitable for the complicated geological environment patterns, it is used in the meteorological forecast and early warning system of geological disasters in Longsheng county. The biggest advantage of the system is that the accuracy of the spatial warning of geological disasters can be improved with the improvement of survey accuracy.

\section{Summary of geological environment in the study area}

Longsheng County is located in the northeast of Guangxi province of China. It is also a typical mountain county. Affected by monsoons, the territory is abundant of rainfall and it is also one of the 5 major rain centers in Guangxi. The average annual rainfall in the region is $1524.4 \mathrm{~mm}$, the maximum annual rainfall is $2032.6 \mathrm{~mm}$ (in 1970), the minimum annual rainfall is $1265.1 \mathrm{~mm}$ (in 1989). The geological disasters are extremely developed in the county. According to the detailed survey in 2007, the number of geological disasters are over 400. The major geological disasters in the county are landslides and collapses, and they have resulted in direct economic losses about 4,156,200 yuan, and have killed 12 people $\mathrm{e}^{[5]}$. Survey data also showed that these geological disasters occurred mainly in the rainy seasons, obviously the geological disasters in Longsheng 
county are induced by rainfall.

Longsheng county is a middle-low mountains area with main peak elevation of $1500 \mathrm{~m}$. Slopes of over $25^{\circ}$ are accounted for $87.2 \%$ of the county's total land area. The county is mainly covered with phyllite, sandstone, shale and mudstone, only a small amount of granite exposed. The exposed rocks can be divided into the following 5 types of engineering geological formations: layered soft phyllite, slate with hard rock group in the south; bedded hard shaly sandstone and the lower soft mudstone intercalated shale formation in the Middle-east and south-east; bedded hard sandstone and siliceous rocks intercalated into the lower shale formation in the West and South West; shale and carbonaceous shale intercalated sandstone rock formation in the North and North West; Loose, soft, strongly weathered granite group in the North-east. This area belongs to North Guangxi uplift of Longsheng fold belt and Yuechengling fold belt in structure. NNE trending folds and faults are well developed. The main folds are San-men anticline, Longsheng anticline, Jinche anticline and Ma-haianticline.

\section{The relationship between the characteristics of geological disasters and rainfall}

The main geological disasters in Longsheng county are landslide and collapse, and their scale is usually small. Small landslides or collapses are accounted for 95\% of the total number of geological disasters, and medium-sized landslides and collapses are only 5\% of the total. There was no large landslide or collapse. Landslides and collapses are dominated by slope deposits and residual soil, followed by strongly weathered rock. Landslides and collapses in the county are affected by many kinds of geological environments such as topography, geological characteristics of the soil, geological structure and human activities. According to the occurrence frequency of geological disasters, the whole county can be divided into 7 high prone areas, 4 prone areas, 5 low prone areas and 1 less prone area.

During detailed investigation, the rainfall data related to 72 landslides or collapses were collected. The data mainly include the values of rainfall on the day of occurrence of geological disasters and the accumulated rainfall of 3 days before disasters occurrence. The statistical results are shown in Fig.1 and Fig.2.

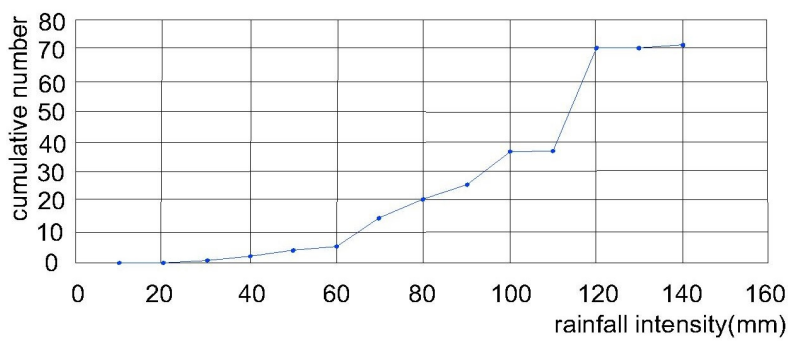

Fig.1 The correlation curve between occurrence quantity of landslides, collapses and the rainfall on the same day

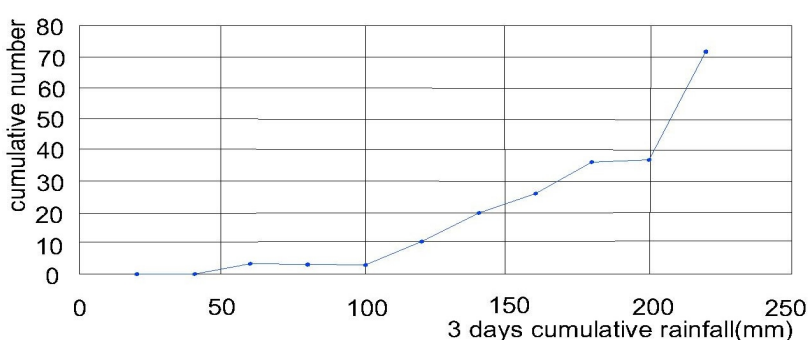

Fig.2 The relationship between occurrence quantity of geological disasters and the accumulated 3 davs rainfall

Fig.1 and Fig.2 show that as the rainfall increases, the occurrence number of landslides and collapses in the county will increase in step shape. The rainfall corresponding to the steps are considered to be critical points, each of them indicate abrupt changes in the number of the geological hazard induced by rainfall ${ }^{[4]}$. There are two critical points in Fig.1 or Fig.2. The critical points corresponding to the daily rainfall were $60 \mathrm{~mm}, 110 \mathrm{~mm}$ and corresponding to 3 days 
cumulative rainfall were $100 \mathrm{~mm}, 200 \mathrm{~mm}$. That's to say, When the rainfall on the occurrence day of disasters is less than $60 \mathrm{~mm}$ or when the accumulated 3 days rainfall before disasters occurrence is less than $100 \mathrm{~mm}$, the occurrence number of landslides or collapses increases slowly. Statistical data showed when the rainfall on the occurrence day increase $20 \mathrm{~mm}$ or when 3 days cumulative rainfall increase $25 \mathrm{~mm}$, the occurrence number of landslides or collapses will increase by 1 to 2 . When the rainfall on the occurrence day is between 60 to $110 \mathrm{~mm}$ or when 3 days cumulative rainfall is between 100 to $200 \mathrm{~mm}$, the increasement of $10 \mathrm{~mm}$ in the day rainfall or $20 \mathrm{~mm}$ in 3 days cumulative rainfall will induce 6 to 7 landslides or collapses. However, when the rainfall on the occurrence day is greater than $110 \mathrm{~mm}$ or when 3 days cumulative rainfall is greater than $200 \mathrm{~mm}$, the increasement of $10 \mathrm{~mm}$ in day rainfall or $10 \mathrm{~mm}$ in 3 days cumulative rainfall will result in 10 to 11 landslides or collapses.

\section{Meteorological early warning and prediction of geological disasters}

Classification of critical rainfall. The critical rainfall mentioned above can be used as geological hazard classification ${ }^{[6]}$. The geological hazard grades of high, middle and low corresponding to the rainfall periods are listed in Table 1.

Table 1 The critical value of rainfall and its risk grade of landslides and collapses induced

\begin{tabular}{|c|c|c|c|}
\hline Dangerous level & & & \\
Precipitation threshold & Low risk & Moderate risk & High risk \\
\hline daily rainfall $(\mathrm{mm})$ & $<60$ & $60 \sim 110$ & $\geq 110$ \\
\hline 3 days cumulative precipitation $(\mathrm{mm})$ & $<100$ & $100 \sim 200$ & $\geq 200$ \\
\hline
\end{tabular}

Classification of meteorological disaster warning and prediction grade. The main idea of grading the meteorological disaster early warning and prediction is: The county is first divided into different geological disaster prone areas according to disasters frequency, and these geological disaster prone areas are taken as the basic units. Then the information values of the geological disaster occurring in each prone area at different rainfall threshold are calculated. According to these information values, the risk grade of geological disaster under different rainfall threshold is got.

The Specific statistical calculation methods are as follows: The $2 \times 2 \mathrm{~km}$ grids are used to divide the prone areas into cells, then the total number of cells in the study area, the number of cells that have landslides or collapses, the total cell number in each prone area, the number of cells that have slides or collapses in each prone area are calculated at different rainfall threshold values. Finally, according to (1) formula, the information value in each prone area is calculated. After that, all the calculated information values are plotted in ascending order(as Fig.3). According to the curve, 5 information distribution segments are divided. These 5 sections are corresponded to 5 geological hazard prediction and warning levels. The greater the value of information is, the higher the level of prediction and warning will be adopted. According to the information values corresponding to different critical rainfalls, the warning grades are determined in each prone area. The formula for calculating the information value in each prone area is as follows: 


$$
I_{i}=\log _{2} \frac{\left(M_{i} / M\right)}{\left(N_{0} / N\right)}
$$

where $M$ is the number of cells in each prone area; $N$ is the total number of cells in the study area; $N_{0}$ is the total number of cells in the study area where geological disasters occur; $M_{i}$ is the total number of cells with geological disasters in each prone area under different levels of rainfall; $I_{i}$ is the information value in each prone area under different rainfall conditions.

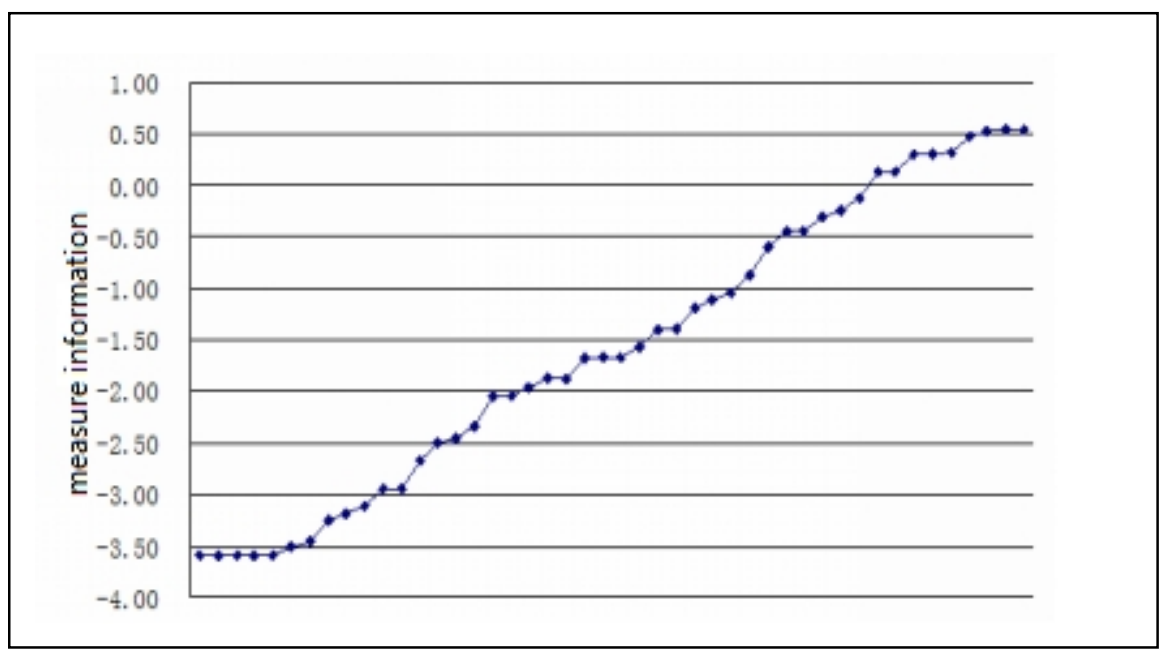

Fig.3 The curve of disaster information value

Dissemination of forecast and warning information. According to the future 24-hour rainfall forecast data released from meteorological departments and the actual cumulative rainfall data before 3 days, the spatial scope and possibility of geological disasters induced by rainfall are analyzed, then the level of geological disaster prediction and warning is determined. This task can be done quickly by referring to Fig.4, Fig.5, and Fig.6.

Table 2 Criteria for the classification of warning and prediction levels

\begin{tabular}{|c|c|c|c|}
\hline $\begin{array}{c}\text { Forecast warning } \\
\text { level }\end{array}$ & $\begin{array}{c}\text { Range of information } \\
\text { value distribution }\end{array}$ & $\begin{array}{c}\text { The possibility of } \\
\text { geological disasters }\end{array}$ & $\begin{array}{c}\text { Number of } \\
\text { partitions }\end{array}$ \\
\hline 1 & $-3.60 \sim-2.95$ & very low & 12 \\
\hline 2 & $-2.67 \sim-1.87$ & lower & 9 \\
\hline 3 & $-1.67 \sim-1.04$ & high & 9 \\
\hline 4 & $-0.87 \sim 0.13$ & higher & 9 \\
\hline 5 & $0.31 \sim 0.91$ & great & 12 \\
\hline
\end{tabular}

All the information values are listed in ascending order and drawn as Fig.3. According to Fig.3, the geological hazard, weather forecast and warning level in the whole area are divided into 5 grades, as shown in Table 2. According to different danger threshold in each prone area, the warning forecast zoning map of Longsheng county are drawn as Fig.4, Fig.5, Fig.6. 


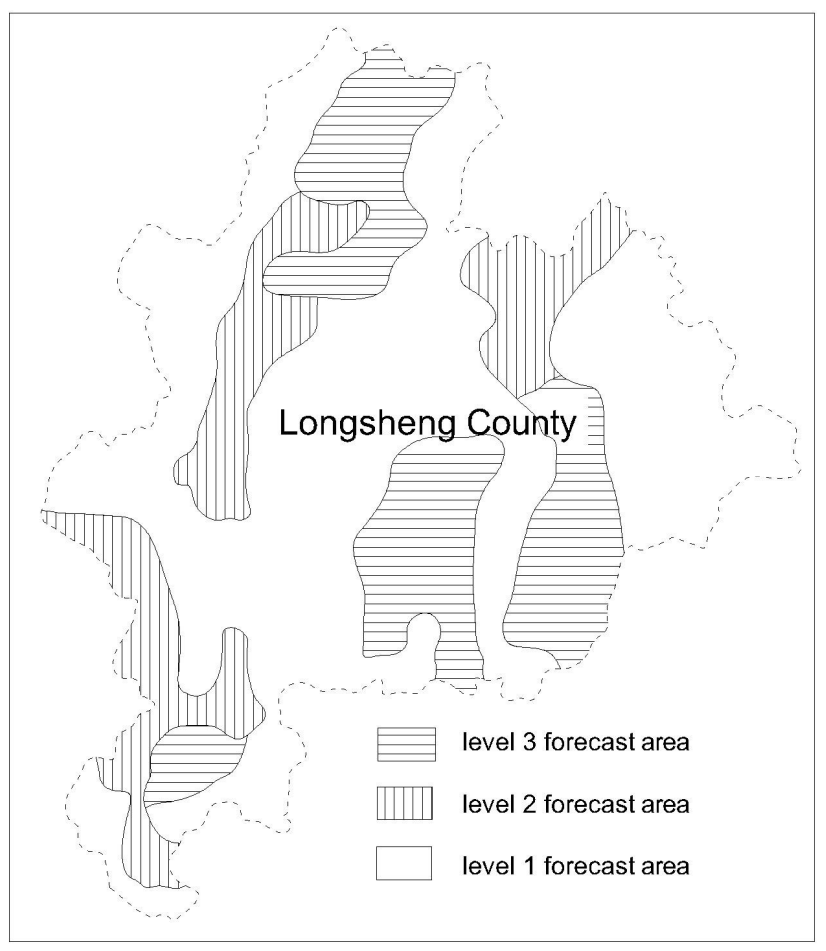

Fig.4 Early warning zoning map for low-risk rainfall thresholds

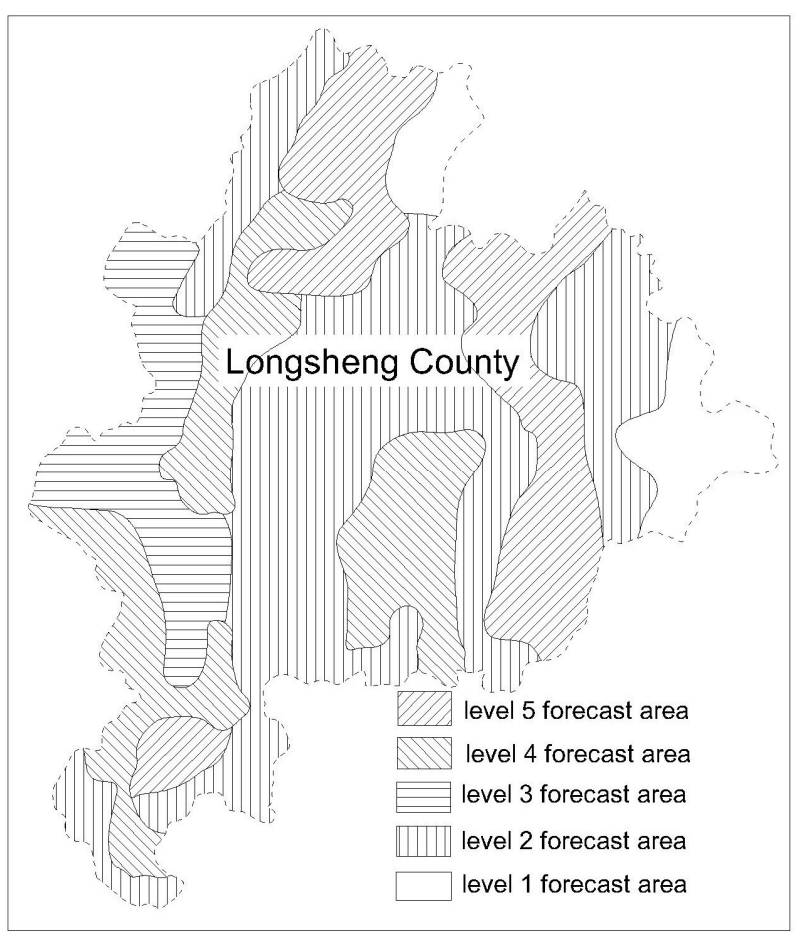

Fig.6 Early warning zoning map for high-risk rainfall thresholds

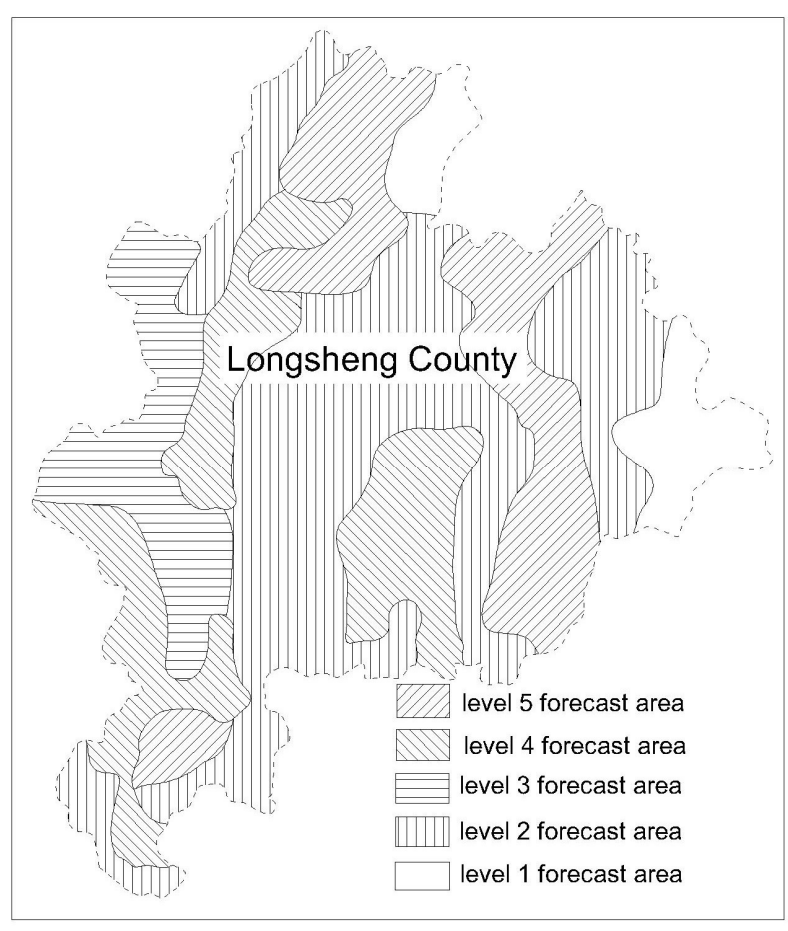

Fig.5 Early warning zoning map for moderate-risk rainfall thresholds 


\section{Conclusions}

Through the statistical analysis of daily rainfall and the accumulated 3 days rainfall, it is found that the number of landslides and collapses in Longsheng county is positively related to the magnitude of rainfall. That is, as the amount of rainfall increases, the number of landslide or collapses will increases in step shape. The rainfall corresponding to the steps are considered to be critical rainfalls, each of them indicate abrupt changes in the number of the geological hazard induced by rainfall. The results of the statistics show that the critical rainfall values in Longsheng county are $60 \mathrm{~mm}$, $110 \mathrm{~mm}$ for the daily rainfall and $100 \mathrm{~mm}, 200 \mathrm{~mm}$ for 3 days cumulative rainfall. With these critical rainfalls, 3 rainfall periods are divided. That is, the three rainfall periods divided by critical daily rainfalls are: $<60 \mathrm{~mm}, 60-110 \mathrm{~mm}$ and $>110 \mathrm{~mm}$, and they are corresponded to low, middle and high risk grades of geological disasters respectively. According to the cumulative rainfall of 3 days, the three rainfall periods are: $<100 \mathrm{~mm}, 100-200 \mathrm{~mm}$ and $>200 \mathrm{~mm}$ and they are also corresponded to low, middle and high risk grades of geological disasters.

The critical rainfalls can also be used to predict the risk of geological disasters in each area in Longsheng county. In the process of geological hazards forcasting, the predicted daily rainfall or 3 days cumulative rainfall are first collected from meteorological departments and checked what the rainfall period it will belong to, then the corresponding forecast chart of geological hazards is adopted to predict the risk of geological hazards in different prone areas.

\section{References}

[1] Shengyuan Yang, Lian Chen, Senlin Yang etc.. Geological Disasters in Guizhou Province [J]. Chinese Journal of Geological Hazard and Control,2006,17 (2):111-114.(In Chinese).

[2] Guangqi Song, Yangui Li, Peilin Zhong. Geological Hazard Meteorological Forecasting and Early Warning Method--A Case Study of Geological Hazard Meteorological Forecast and Early Warning in Sichuan Province [J]. Heatology and Geology Engineering Geology, 2004 (2): 33-36.(In Chinese)

[3] Hongbing Zhang. Study on Early Warning Model of Geological Hazards in Yunnan Province [J]. Journal of Geological Hazards and Control,2006,17(1): 40-42.(In Chinese)

[4] Chuanzheng Liu, Yanhui Liu. Geological Hazards Regional Early Warning Principle and Explicit Early Warning System Design Study [J]. Journal of Hydrogeology and Engineering Geology. 2007 (6); 109-115.(In Chinese)

[5] Li Jiang. Detailed Investigation Report of Geological Disasters in Guangxi County, Longsheng [R]. Guilin: Guangxi Geological Environment Monitoring Station, 2007.(In Chinese).

[6] An Li, Shengshan Hou, Pinggen Zhou. Landslide Research Yancheng District, Ya'an City, Sichuan Province Induced by Rainfall [J]. Journal of Chinese and Prevention of Geological Disasters, 2007,18 (1); 15-17.(In Chinese) 